\title{
„Keine Angst vor Strahlen“: DGKJ veröffentlicht GPR-Elternratgeber
}

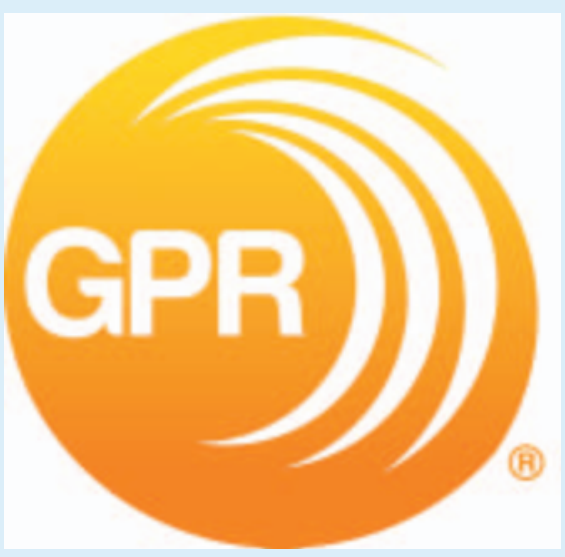

Die Deutsche Gesellschaft für Kinder- und Jugendmedizin e. V. (DGKJ) hat eine Elterninformation der Gesellschaft für Pädiatrische Radiologie e. V. (GPR) auf ihrer Webseite veröffentlicht. Unter dem Titel „Keine Angst vor Strahlen" sind die wichtigsten Informationen für Eltern zusammengefasst, deren Kindern eine Röntgen- oder CTUntersuchung bevorsteht.
Darin wird erläutert, was Röntgenstrahlen sind, warum Strahlenschutz so wichtig ist und was Eltern selbst hierfür tun können.

Zu der Elterninformation gelangen Sie auf der DGKJ-Webseite:

www.dgkj.de/eltern > Spezialistenporträts/Untersuchungsmethoden > Röntgen- und Computertomografieuntersuchung 